\title{
Public health importance of Brachiola algerae (Microsporidia) - an emerging pathogen of humans
}

\author{
Govinda S. Visvesvara' ${ }^{1}$, Hercules Moura ${ }^{1,2,3}$, Gordon J. Leitch ${ }^{4}$, David A. Schwartz ${ }^{5}$ and Lihua X. Xiao ${ }^{1}$ \\ ${ }^{1}$ Division of Parasitic Diseases, National Center for Infectious Diseases, Centers for Disease Control and Prevention, Public \\ Health Service, Department of Health and Human Services, Atlanta, Georgia, USA; \\ ${ }^{2}$ AREF, Atlanta, Georgia, USA; \\ ${ }^{3}$ Present address: Mass Spectrometry Laboratory, Emergency Response and Air Toxicants Branch, Division of Laboratory Sci- \\ ences, CDC, Atlanta, Georgia, USA; \\ ${ }^{4}$ Department of Physiology, Morehouse School of Medicine, Atlanta, Georgia, USA; \\ ${ }^{5}$ Guest Researcher, National Center for Infectious Diseases, Atlanta, Georgia, USA
}

Key words: Microsporidia, Brachiola algerae, cell culture, genotype, immunoblot, PCR products, sequencing

\begin{abstract}
Brachiola algerae (Vavra et Undeen, 1970), a parasite of Anopheles mosquitoes, has also been isolated from a human cornea, a cutaneous nodule and deep muscle tissue. All three human isolates of $B$. algerae are morphologically, serologically, and genetically similar to the mosquito-derived isolates including the original isolate of Vavra and Undeen. All of these isolates grew well in mammalian cell cultures at $37^{\circ} \mathrm{C}$ and produced spores. Transmission electron microscopy revealed that all developmental stages including meronts, sporoblasts and spores were diplokaryotic and developed in direct contact with the host cell cytoplasm, a feature characteristic of the genus Brachiola. Spores of all isolates reacted well, in the immunofluorescence assay, with the rabbit anti-B. algerae serum. In the immunoblot assay, although the overall banding patterns of the human and mosquito isolates were similar, minor differences could be discerned. Sequencing of the PCR products of the amplified SSU rRNA gene revealed the existence of two distinct genotypes; the original mosquito (Undeen) isolate belonged to genotype 1 and the isolate from cornea and that from the deep muscle biopsy to genotype 2, whereas the isolates from a mosquito and one of the other two human isolates (one from skin abscess) had both genotypes, 1 and 2 . It is known that spores of mosquito-derived $B$. algerae can not only proliferate in mammalian cell cultures at $37^{\circ} \mathrm{C}$ but also can infect mice when injected into footpads or deposited on the corneal surface. These observations indicate that the spores have potential to be a risk factor for humans, especially those with immunodeficiency.
\end{abstract}

Although more than 1,000 species belonging to about 100 genera are included in the phylum Microsporidia, only 14 species belonging to 8 genera have been identified as agents of human disease. They are: Enterocytozoon bieneusi, Encephalitozoon cuniculi, E. hellem, E. intestinalis, Brachiola vesicularum, B. algerae, B. connori, Nosema ocularum, Vittaforma corneae, Pleistophora ronneafiei, Trachipleistophora hominis, T. anthropophthera, and a collective genus Microsporidium (to include $M$. africanum, $M$. ceylonensis). Microsporidiosis has increasingly been recognized as a burgeoning problem in HIV/AIDS patients. Although Enterocytozoon bieneusi is the most commonly identified etiologic agent in AIDS patients with chronic diarrhoea, other microsporidian species such as $B$. algerae, B. connori, B. vesicularum, E. cuniculi, $E$. hellem, $E$. intestinalis, $V$. corneae, $M$. africanum, $M$. ceylonensis, $N$. ocularum, $P$. ronneafiei, $T$. hominis and $T$. anthropophthera have also caused human infections (Didier and Bessinger 1999).

Nosema algerae Vavra et Undeen, 1970 originally isolated from Anopheles stephensi Liston mosquitoes was known to be primarily a pathogen of mosquitoes (Vavra and Undeen 1970). However, Sprague in 1974 described Nosema connori (now known as Brachiola connori) that caused a disseminated disease in an athymic infant and Cali et al. in 1991 described $N$. ocularum that caused corneal ulceration. Recently, a new genus and species of a microsporidian, that caused myositis in an AIDS patient, was described as Brachiola vesicularum (Cali et al. 1998). Baker et al. (1994) and Muller et al. (2000) have shown that $N$. algerae does not cluster with typical representatives of the genus Nosema based on the sequence data on the small subunit rRNA gene. Based on this molecular phylogeny data and other characteristic morphological features, $N$. algerae has been recently transferred to the newly created genus Brachiola Lowman, Takvorian et Cali, 2000 and is now designated as $B$. algerae (Vavra et Undeen, 1970) (Lowman et al. 2000).

This paper was presented at the NATO Advanced Research Workshop "Emergent Pathogens in the 21st Century: First United Workshop on Microsporidia from Invertebrate and Vertebrate Hosts", held in Ceské Budejovice, Czech Republic, July 12-15, 2004. 


\section{MATERIALS AND METHODS}

Isolates and their histories. Of the three human isolates, one (CDC:V404) was obtained from the corneal scraping and corneal biopsy of a 67-year-old immunocompetent male patient (Visvesvara et al. 1999a, Font et al. 2000), the second (CDC:V422) from the skin biopsy of an 11-year-old boy with acute lymphocytic leukaemia (ALL) in remission. He had received chemotherapy in the recent past and was stable. He was admitted to the hospital with six to eight weeks of progressive erythematous skin nodules on the legs, buttocks, and hand that occasionally drained purulent material. He had no other gastrointestinal, genitourinary or respiratory symptoms. The initial clinical diagnosis was lymphoma cutis vs. Nocardia. A 4-mm punch biopsy from right foot was processed for culture and histopathology. One half of the specimen was fixed in buffered formalin and the other half was macerated and inoculated into monkey kidney (E6) cells and human lung fibroblasts (HLF) at $37^{\circ} \mathrm{C}$ cell cultures and incubated at $37^{\circ} \mathrm{C}$. The third isolate (CDC:V521) was from a deep muscle biopsy of an immunosuppressed 57-year-old female (Coyle et al. 2004). The two mosquito isolates studied consisted of the original B. algerae isolate (Vavra and Undeen 1970) - obtained from Dr. Undeen and designated as Undeen isolate - and an isolate (CDC:V395) derived from naturally infected $A$. stephensi mosquitoes (Moura et al. 1999). All isolates were grown on monkey kidney (E6) cell cultures and human lung fibroblasts (HLF) at $37^{\circ} \mathrm{C}$ (Visvesvara et al. 1991, Moura et al. 1999). For some experiments the microsporidia growing in E6 cultures were also maintained at $30^{\circ} \mathrm{C}$ (Moura et al. 1999). Spores were harvested periodically and then purified by centrifugation with Percoll gradient at $500 \times g$ for $20 \mathrm{~min}$ at $4^{\circ} \mathrm{C}$ as described previously (Visvesvara et al. 1999b, Moura et al. 1999). Some of the flasks containing the infected cell cultures were also held at $37^{\circ} \mathrm{C}$ for more than 9 months with weekly changes of the culture medium.

Electron microscopy (EM). E6 and HLF monolayers infected with microsporidia were treated with trypsin-EDTA as described elsewhere (Visvesvara et al. 1991, Moura et al. 1999) and the detached cell layers were washed with Hank's balanced salt solution (HBSS) and fixed with $2.5 \%$ glutaraldehyde in 0.1 $\mathrm{M}$ cacodylate buffer, $\mathrm{pH} 7.4$ at $4^{\circ} \mathrm{C}$. Anopheles stephensi mosquitoes that were naturally infected with $B$. algerae were obtained from the CDC mosquito colony, fixed in glutaraldehyde as above, and processed for transmission electron microscopy (TEM). For scanning electron microscopy (SEM), the tissue culture cells were dehydrated through a graded series of ethanol, dried in a critical-point drier, and sputter-coated with goldpalladium and examined with a JEOL JSM 820 scanning electron microscope, as described previously (Visvesvara et al. 1991). For TEM, the specimens, after fixing the cells in $2.5 \%$ glutaraldehyde buffered with cacodylate, were postfixed in a $1 \%$ osmium tetroxide solution, dehydrated in ethanol and embedded in Epon 812. Ultrathin sections were cut, stained with uranyl acetate and lead citrate, and examined with a JEOL 1200 EX transmission electron microscope as described previously (Visvesvara et al. 1991).

Indirect Immunofluorescence Test (IIF). Spores of all $B$. algerae isolates were harvested from culture supernatants and washed three times in HBSS before counting in a haemacytometer. They were then suspended in HBSS containing $1 \%$ Formalin to obtain $10^{7}$ spores per $\mathrm{ml}$, and processed for the IIF test as described previously (Visvesvara et al. 1994). The corneal, skin, and muscle biopsy specimens were also either stained with the chromotrope 2R (Weber et al. 1992) and the quick-hot Gramchromotrope procedures (Moura et al. 1997) or evaluated by IIF (Visvesvara et al. 1994).

SDS-polyacrylamide gel electrophoresis (PAGE) and immunoblotting. Spore proteins were extracted and electrophorectically separated and transferred to polyvinylidene difluoride (PVDF) membranes as described previously, with minor modifications (Visvesvara et al. 1994). Briefly, purified spores of the four (V395, V404, V422 and the Undeen) B. algerae isolates, as well as E6 cells were suspended in a sample buffer containing $2.5 \%$ sodium dodecyl sulfate (SDS) and $2.25 \mathrm{M}$ urea and the mixture was heated at $65^{\circ} \mathrm{C}$ for $15 \mathrm{~min}$. Proteins extracted from approximately $5 \times 10^{7}$ spores were loaded onto each lane of precast $4-20 \%$ linear gradient Tris- $\mathrm{HCl}$ gels, measuring $8.7 \mathrm{~cm}$ $\times 13.3 \mathrm{~cm} \times 1 \mathrm{~mm}$ (Criterion, BioRad Laboratories, Hercules, CA). After protein loading, the gels were subjected to electrophoresis using a discontinuous buffer system, which consisted of a freshly prepared upper chamber solution containing $41 \mathrm{mM}$ Tris, $40 \mathrm{mM}$ boric acid and $0.1 \%(\mathrm{w} / \mathrm{v})$ SDS and a lower chamber buffer solution containing $81.2 \mathrm{mM}$ Tris, $23 \mathrm{mM}$ boric acid and $1.35 \mathrm{mM}$ EDTA ( $\mathrm{pH} 8.9$ ). The separated proteins were either stained with silver stain or with GelCode Blue stain reagent (Pierce Chemical Company, Rockford, IL), or electrophorectically transferred to PVDF membranes and reacted with a 1:1,000 dilution of rabbit anti-B. algerae serum (CDC:V404), and processed as before (Visvesvara et al. 1994). Gels and blots images were acquired and analysed using LabWorks ${ }^{\mathrm{TM}}$ software (UVP Inc., Upland, CA).

PCR and sequencing analyses. DNA was extracted from spores of all five $B$. algerae isolates growing on E6 cells by alkaline digestion (culture pellets in $33.3 \mu \mathrm{l}$ of $1 \mathrm{M} \mathrm{KOH}$ and 9.3 $\mu \mathrm{l}$ of $1 \mathrm{M}$ Dithiothreitol at $65^{\circ} \mathrm{C}$ for $15 \mathrm{~min}$, followed by neutralisation with $4.3 \mu 1$ of $25 \% \mathrm{HCl}$ buffered with $80 \mu 1$ of $2 \mathrm{M}$ Tris-HCl, $\mathrm{pH}$ 8.3), phenol-chloroform extraction, and DNA purification using QIAamp DNA Stool Mini Kit (QIAGEN, Valencia, CA). The small subunit rRNA (SSU rRNA) gene of all $B$. algerae isolates was amplified using primers 5'-CACCAGGT TGATTCTGCCTGA (MICRO-F) and 5'-CCAACTGAAA CCTTGTTACGACTT (1492N4). The PCR product was sequenced in both directions on an ABI377 autosequencer (Applied Biosystems, Foster City, California). Some of the PCR products were cloned into a pGEM-T Vector (Promaga, Madison, WI), and 8 clones of plasmids containing the SSU rRNA insert were sequenced in both directions for each $B$. algerae isolate. The sequences obtained were aligned with each other and the SSU rRNA sequences of other microsporidian parasites obtained from the GenBank, using the Wisconsin Package Version 9.0 (Genetics Computer Group, Wisconsin). A neighbourjoining analysis was done with the program TreeconW (Van de Peer and Wachter 1994), based on the evolutionary relatedness and calculated with the Kimura 2-parameter model.

\section{RESULTS}

\section{Parasite growth and ultrastructure}

The three (V404, V422, V521) human parasites and the two mosquito parasites (the Undeen and V395) grew well 

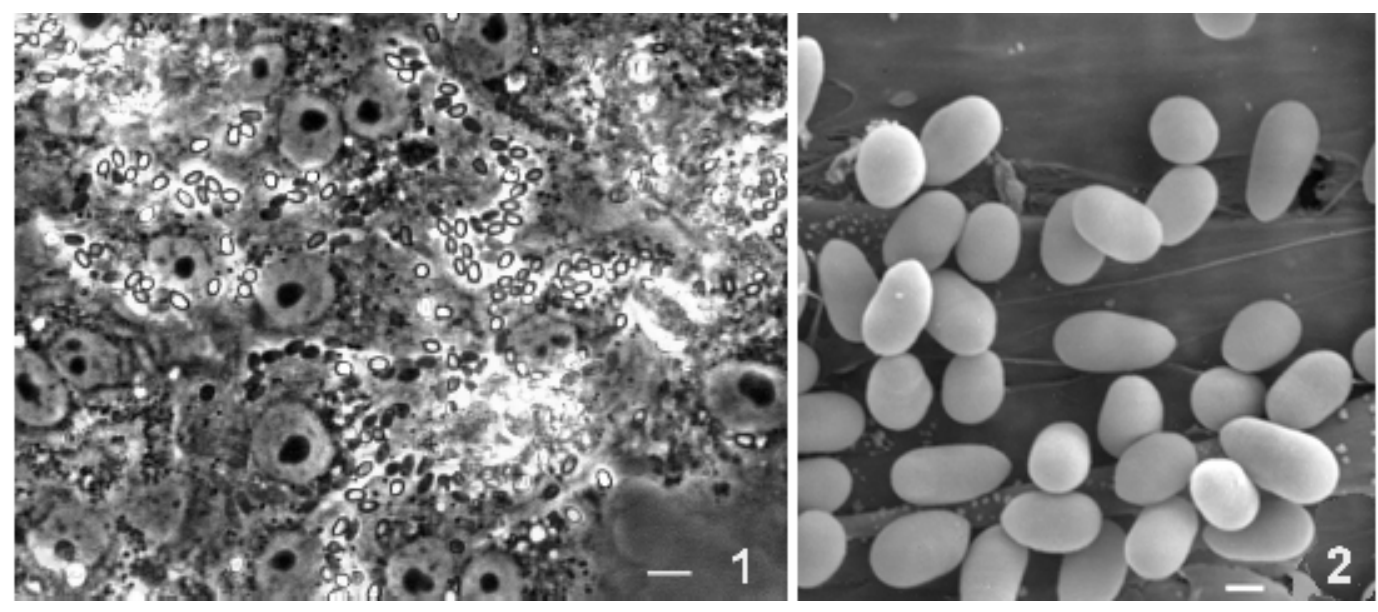

Fig. 1. Monkey kidney cells (E6) heavily infected with Brachiola algerae (CDC:V521). Phase contrast. Fig. 2. A scanning electron micrograph of an HLF cell culture infected with B. algerae (CDC:V422). Note the egg-shaped spores. Scale bars: Fig. $1=10 \mu \mathrm{m}$; Fig. $2=1 \mu \mathrm{m}$.

in both E6 and HLF cell cultures at $37^{\circ} \mathrm{C}$ and released spores continuously into the cell culture medium. In the initial stages of culture and growth, few spores were seen internalised and were seen usually surrounding the host cell nucleus. During this time the culture medium from each flask was removed and fresh medium added. Spores present in the spent medium were centrifuged and the sedimented spores were reinoculated into original culture flasks. By the third week of culture the microsporidia had spread to about one third of the cell culture monolayer and most of the cytoplasm of the host cells were filled with spores usually surrounding the nucleus of each host cell (Fig. 1). At this time the reinoculation of the sedimented spores was discontinued. By about the second month of continuous culture the parasites had adapted well to culture conditions and almost the entire monolayer was filled with spores and developing stages of the parasite. Large numbers of spores were also found lying free in the supernatant medium. The spores appeared to be birefringent when examined with a microscope equipped with phasecontrast optics. Some of the spores had extruded their polar filaments.

Scanning electron microscope images of HLF cells distended with spores of the two human (CDC:V404 and CDC:V422) and those of two mosquito (the Undeen and V395) isolates appeared as though the spores were covered with a muslin-like cloth. Further, masses of spores were seen being released from the host cells. The spores and the surrounding areas appeared to be covered with tiny particles that gave the disrupted cells a speckled appearance. At higher magnification the spores appeared to be egg-shaped and smooth-walled (Fig. 2).

Transmission electron microscopy (TEM) revealed that all developing stages and spores of the two human (CDC:V404 and CDC:V422) and the two mosquito isolates derived from cell culture as well as the mosquito isolates growing within the mosquito gut, were found within the host cell cytoplasm without any parasitophorous vacuole (Figs. 3, 4). Developing stages consisted of meronts or proliferating stages, sporogonial stages and mature spores. All stages possessed a single diplokaryon. They were also characterized by the presence of abundant ribosomes either dispersed freely in the cytoplasm of the parasite cell or attached to the endoplasmic reticulum. The meronts appeared to be oval and elongate with the diplokaryotic nucleus occupying almost the entire organism. The diplokaryon was bounded by an envelope that consisted of two unit membranes. The two nuclei of the diplokaryon abutted each other and at the point of contact the four unit membranes were clearly seen indicating that there was no fusion of the membranes between the apposed nuclei. Multiple dense areas, interpreted as chromosomes, were present within the nucleus. The cell surface or the plasmalemma was covered with a thick electron-dense material but in some cases this surface appeared to contain electron-lucent regions at regular intervals. The parasite surface was also covered with vesiculotubular structures that extended into the host cell cytoplasm (Figs. 3D, 4A). In some cases, specifically within the mosquito gut, the parasite cell surface formed bulges or invaginations that protruded into the host cell cytoplasm (Fig. 3D). As development proceeded the vesiculotubular structures detached from the parasite cell surface and appeared within the host cell cytoplasm as bundles of tubules that were held tightly together (Fig. 4A, C). In the meanwhile the parasite surface became smooth and thickened indicating that differentiation to the sporogonial stage has commenced. The sporoblasts had extremely dense cytoplasm with the diplokaryotic nuclei occupying the central area. Abundant ribosomes surrounded the nucleus. Eight to nine cross-sections of the polar filament were usually seen within the cytoplasm of a majority of the sporogonial stages. The polaroplast appeared to be highly tubular in the central area and lamellar in the periphery. The spores 


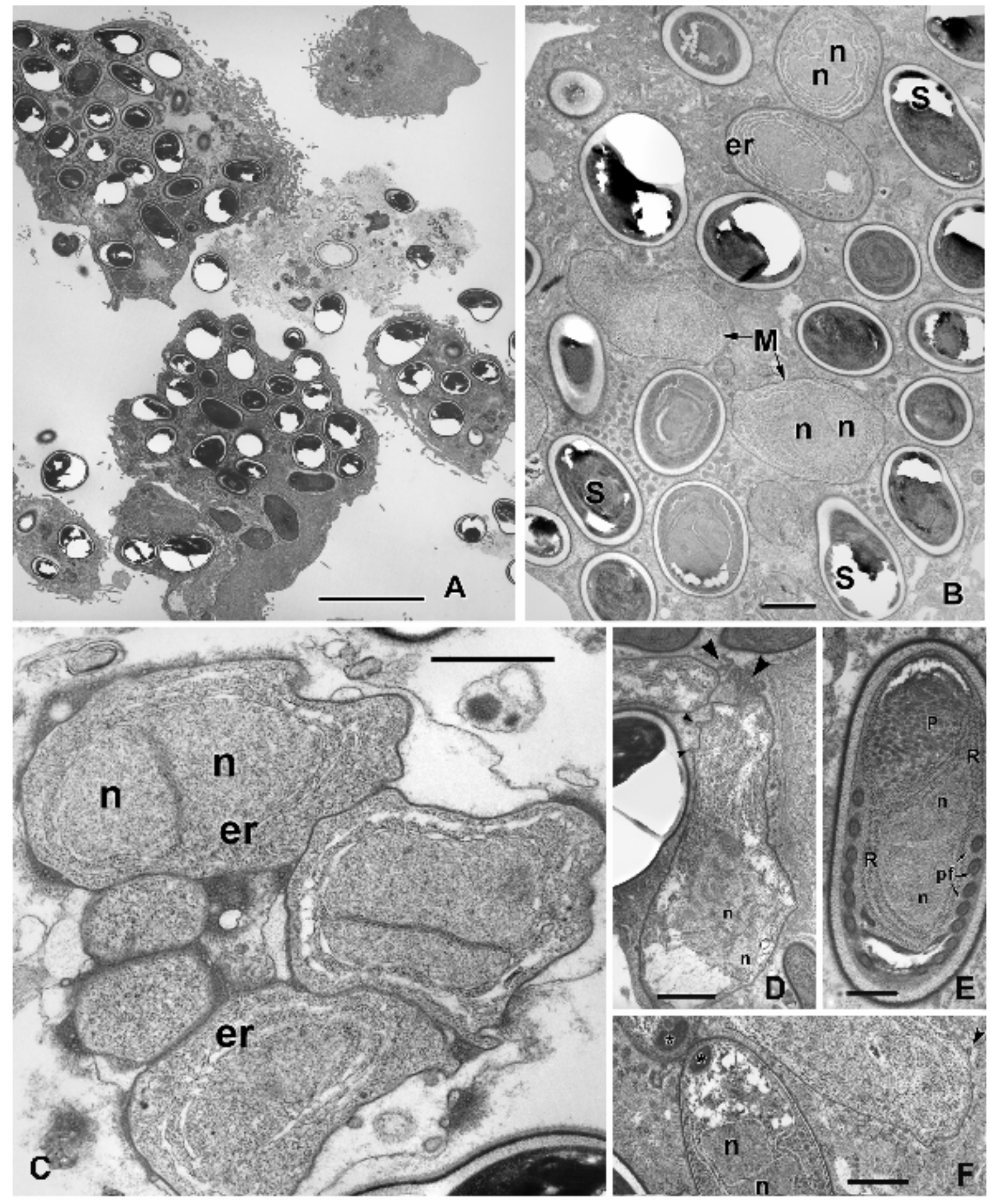

Fig. 3. Transmission electron micrographs of Anopheles stephensi mosquitoes infected with Brachiola algerae. A-The abdomen of the mosquitoes is filled with spores and developing stages of B. algerae. B - Various developmental stages of B. algerae in the mosquito gut. C - Proliferating forms (meronts) with diplokaryotic nucleus. D - A meront in the mosquito gut. Note the bulges or invaginations (small arrowheads) on the meront cell membrane; the highly tubular structures (large arrowheads) emanating from one end of the meront cell surface are seen extending into the host cell cytoplasm. $\mathbf{E}-$ A spore with electron-dense exospore, electron-lucent endospore, ribosomes, polaroplast (P) and 7 to 8 cross-sections of the polar filament (pf). F - A dividing sporoblast showing anchoring disk $\left(^{*}\right)$ and a meront with surface blebs or invaginations (arrowhead). er - endoplasmic reticulum; $M-$ meront; $n-$ nucleus; $\mathrm{P}$ - polaroplast; pf - polar filament coils; $\mathrm{R}$ - ribosomes; $\mathrm{S}$ - spore. Scale bars: $\mathrm{A}=10 \mu \mathrm{m} ; \mathrm{B}=1 \mu \mathrm{m} ; \mathrm{C}, \mathrm{F}=2 \mu \mathrm{m} ; \mathrm{D}, \mathrm{E}=0.5 \mu \mathrm{m}$. 


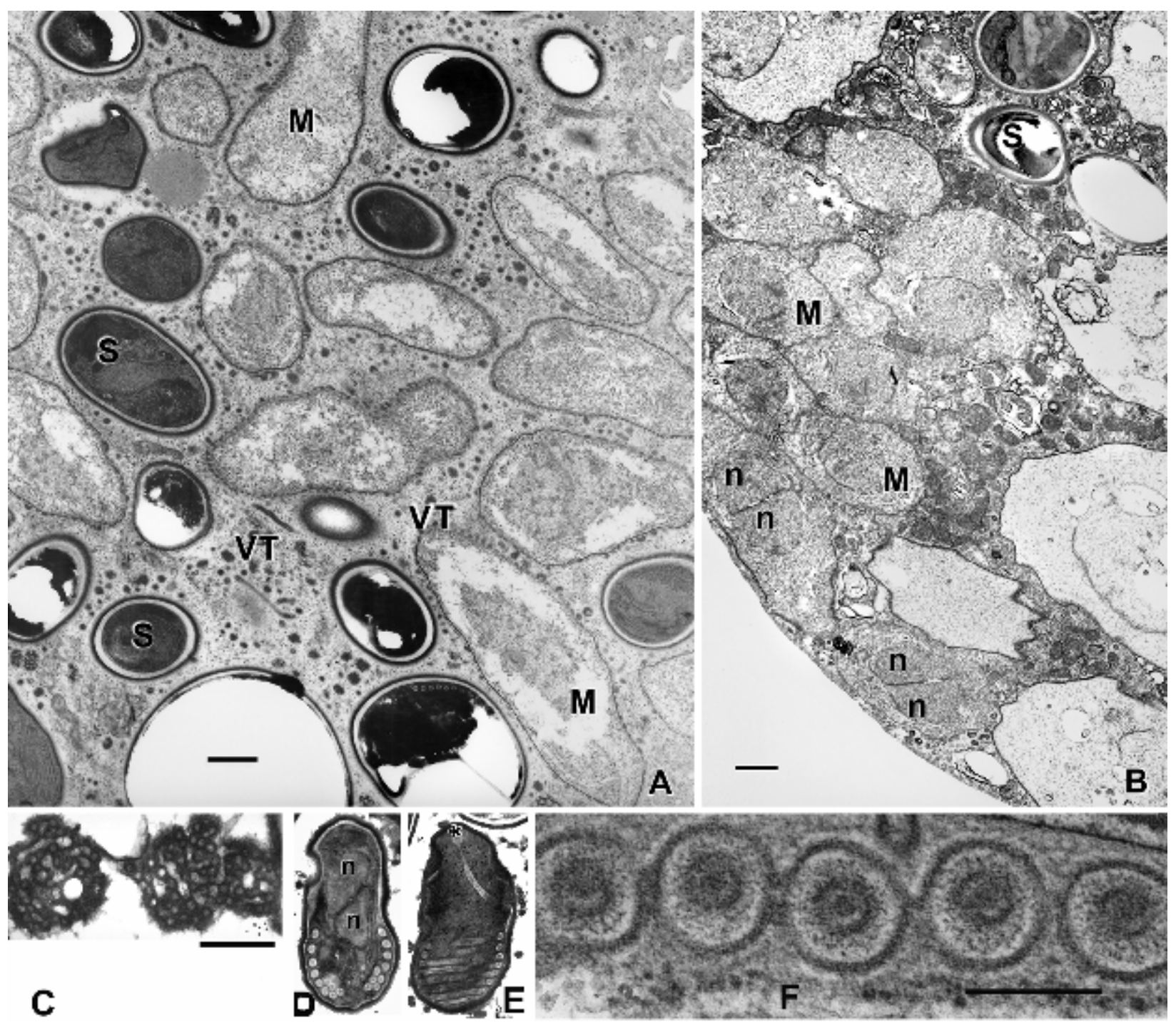

Fig. 4. Developing stages of Brachiola algerae in E6 cell culture. A - CDC:V404 isolate. Note the vesiculotubular structures (VT) associated with the meront cell membrane and aggregated in the cytoplasm of the host cell. B-CDC:V422 isolate. C-Aggregates of vesiculotubular structure lying free in the E6 cell cytoplasm. D, E-Mature spores showing nucleus (n) and anchoring disk $(*)$. F - Cross-section of polar filament of a spore derived from CDC:V404 in E6 cell culture. M - meront; $\mathrm{n}$ - nucleus; S - spore; VT vesiculotubular structure. Scale bars: $A, B=1 \mu \mathrm{m} ; C, D, E=2 \mu \mathrm{m} ; \mathrm{F}=200 \mathrm{~nm}$.

measured $2.4 \mu \mathrm{m}$ by $4 \mu \mathrm{m}$, usually about $3 \mu \mathrm{m}$, and were smooth-walled. The spore was bounded by an outer electron-dense exospore and an inner electron-lucent endospore. The number of polar filament coils ranged from 8 to 11 , sometimes in two rows; coils present anteriorly were slightly larger than those at the posterior end (Fig. 3E, Fig. 4D, E). The polar filament had a central core surrounded by two layers (Fig. $4 \mathrm{~F}$ ). The extruded polar filaments seen in many of the spores measured 15-22 $\mu \mathrm{m}$ in length. Although spore contents were dense, the lamellar polaroplast could be discerned at one end and a vacuole at the opposite end in some spores. These morphological features were consistent with those described for $B$. algerae.

\section{IIF assay}

Spores of the corneal isolate (CDC:V404) reacted with the homologous anti-CDC:V404 serum and produced bright apple green fluorescence at a dilution of 4,096. Although, all other isolates also reacted well with anti-CDC: V404 the titre, however dropped to 512. The spores present in the formalin-fixed tissue sections also reacted well with the anti-CDC:V404 serum at a dilution of 256 and produced apple green fluorescence (Fig. 5B, E, H, I).

\section{SDS-PAGE and immunoblotting}

After GelCode Blue or silver staining, the electrophorectically-separated proteins extracted from four (Undeen, V395, V404, V422) B. algerae isolates exhibited a 


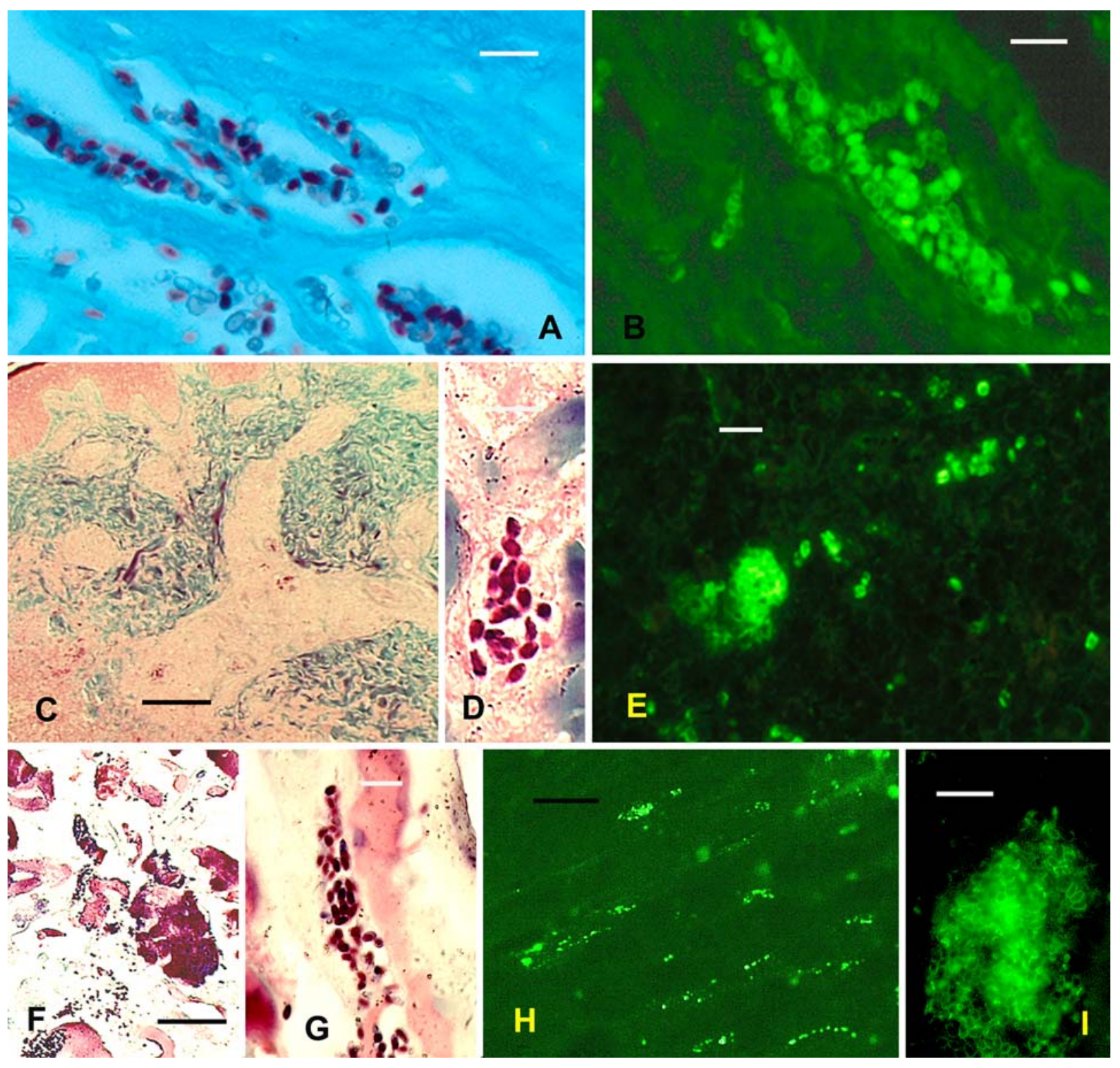

Fig. 5. Human infections with Brachiola algerae. Patients' tissue sections stained with Gram chromotrope (A, C, D, F, G) and by immunofluorescent reaction (B, E, H, I). A section of a cornea of patient 1 stained with Gram chromotrope (A) and a different section from the same patient reacted initially with rabbit anti-B. algerae (CDC:V404) and subsequently with FITC-conjugated goat antirabbit $\operatorname{IgG}(\mathbf{B})$. A section of a cutaneous abscess biopsy of patient 2 stained with Gram chromotrope $(\mathbf{C}, \mathbf{D})$ and a different section $(\mathbf{E})$ reacted with anti-B. algerae (CDC:V404) as above. A section of a muscle biopsy of patient 3 stained with Gram chromotrope (F, G) and a different section $(\mathbf{H}, \mathbf{I})$ reacted with anti-B. algerae (CDC:V404) as above. Scale bars: A, B, D, E, G, I = $10 \mu \mathrm{m} ; \mathrm{C}, \mathrm{F}, \mathrm{H}=100$ $\mu \mathrm{m}$.

complex but similar pattern producing approximately 60 bands ranging from 10 to $200 \mathrm{kDa}$ (not shown). Proteins transferred to PVDF membranes reacted extensively when probed with rabbit anti-B. algerae serum (Fig. 6). Despite the overall similar pattern, immunoblots of the homologous CDC:V404 extract (Fig. 6, lane 4) revealed at least 26 dark prominent bands ranging from 10 to $200 \mathrm{kDa}$, along with a number of unique bands (at arrows) that hadmolecular masses of $\sim 158,54,44,40,25$ and $18 \mathrm{kDa}$. No reaction was detected with the E6 cells control extracts.

\section{Sequence analysis}

Near complete SSU rRNA sequences were obtained from three human isolates (CDC:V404, CDC:V422, and CDC:V521) and the two mosquito isolates (Undeen and CDC: V395). The SSU sequence from the Undeen isolate was identical to a sequence deposited in the GenBank (accession No. AF024656) which was obtained from a research colony of naturally infected mosquitoes in Georgia. Two sequences obtained from CDC:V404 were identical to each other and differed from the sequence (GenBank 

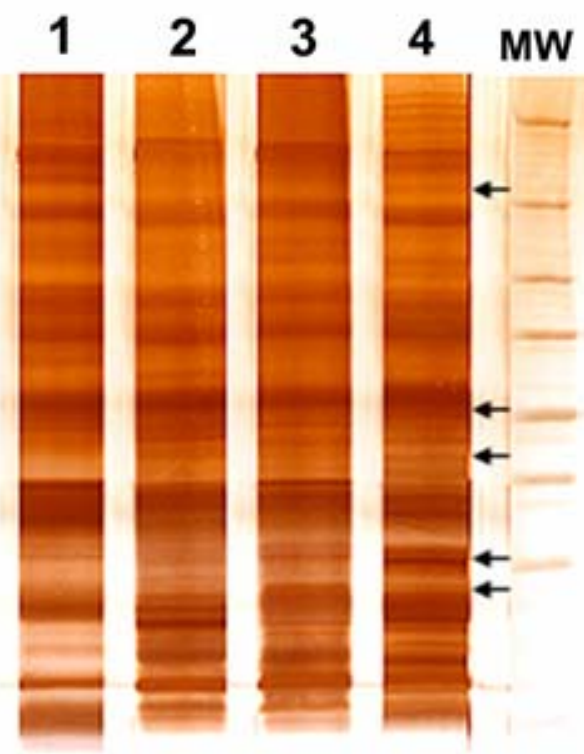

\section{(kDa) 250 150 100 \\ 75 50 37

Fig. 6. Western blot profiles of two mosquito and two human isolates of Brachiola algerae after reaction with anti-B. algerae (CDC:V404) serum. Lane 1 - Undeen; lane 2-CDC:V395; lane 3-CDC:V404; lane 4-CDC:V422. Arrows indicate some of the differences seen in the banding pattern between CDC:V404 and other isolates.

accession No. AF069063) previously obtained from a $B$. algerae isolate from Anopheles stephensi mosquitoes in Germany (Muller et al. 2000) by one nucleotide change (A to $\mathrm{T}$ at nucleotide 189). The SSU sequence obtained from the muscle biopsy isolate (CDC:V521) was identical to sequences from CDC:V404, with the exception of an insertion of A after nucleotide 1190. The sequence from Undeen isolate, however, differed from sequences obtained from CDC:V404 and CDC:V521 by having two nucleotide deletions and 11 nucleotide changes (Fig. 7). These two types of sequences were thus referred to as genotype 1 (Undeen) and genotype 2 (CDC:V404 and CDC:V521). Representatives of the SSU sequences of the two genotypes were submitted to the GenBank database under accession numbers AY963289 and AY963290.

Sequence analysis of PCR products generated from CDC:V422 from the second human case and CDC:V395 from mosquitoes indicated that both $B$. algerae isolates had heterogeneous SSU rRNA sequences. This was evident in the electropherograms generated by ABI377, which showed underlying sequences for both CDC:V422 and CDC:V395. These PCR products were cloned into a pGEM-T vector, and 7 or 8 recombinant clones of which were sequenced for each isolate. Two types of sequences were generated from each isolate, and these sequences showed high homology to either genotype 1 or genotype 2 sequences obtained from Undeen and CDC:V404 isolates. One or two mutations were sometimes present in these sequences, but this was within the error rate of the Taq DNA polymerase. Genotype 1 sequence was the predominant sequence type in CDC:V395, with 5 of 7 sequences

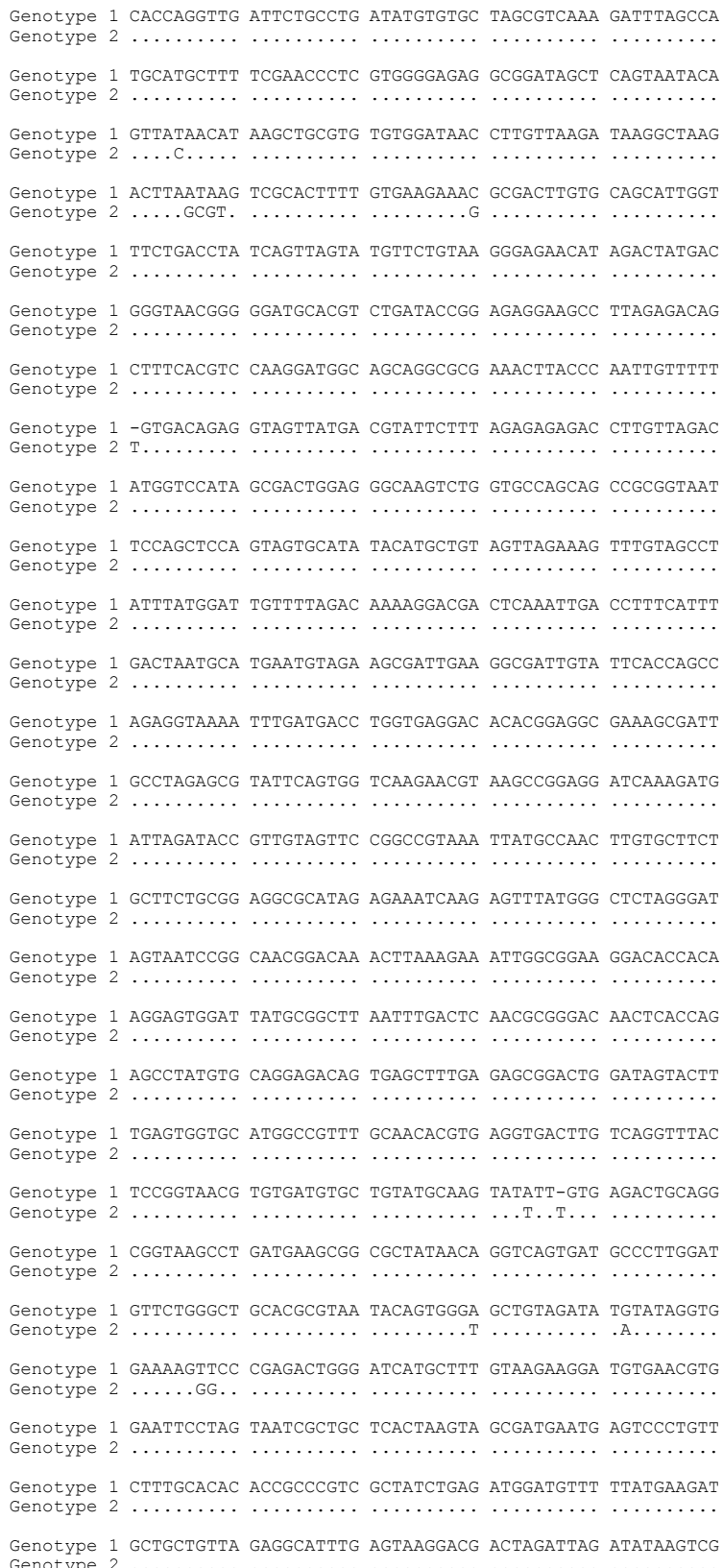

Fig. 7. Differences in the SSU rRNA sequences between $\mathrm{Bra}$ chiola algerae mosquito isolate (Undeen) (genotype 1) and the human isolate (CDC:V404) (genotype 2). Dots denote nucleotides identical to those of genotype 1 , and dashes denote nucleotide deletions.

obtained belonging to this type of sequence. In contrast, genotype 2 sequence was the predominant sequence in CDC:V422, with 6 of 8 sequences belonging to genotype 2. As a control, we also cloned the Undeen PCR product and sequenced 8 clones, all of which had the genotype 1 sequence (Fig. 8).

The stability of heterogeneous genotypes in CDC:V395 and CDC:V422 was not affected by culture selection at different temperatures $\left(30^{\circ} \mathrm{C}\right.$ and $\left.37^{\circ} \mathrm{C}\right)$. Cultivation of CDC:V395 and CDC:V422 at $30^{\circ} \mathrm{C}$ and $37^{\circ} \mathrm{C}$ for several weeks did not eliminate any genotype from the culture nor 


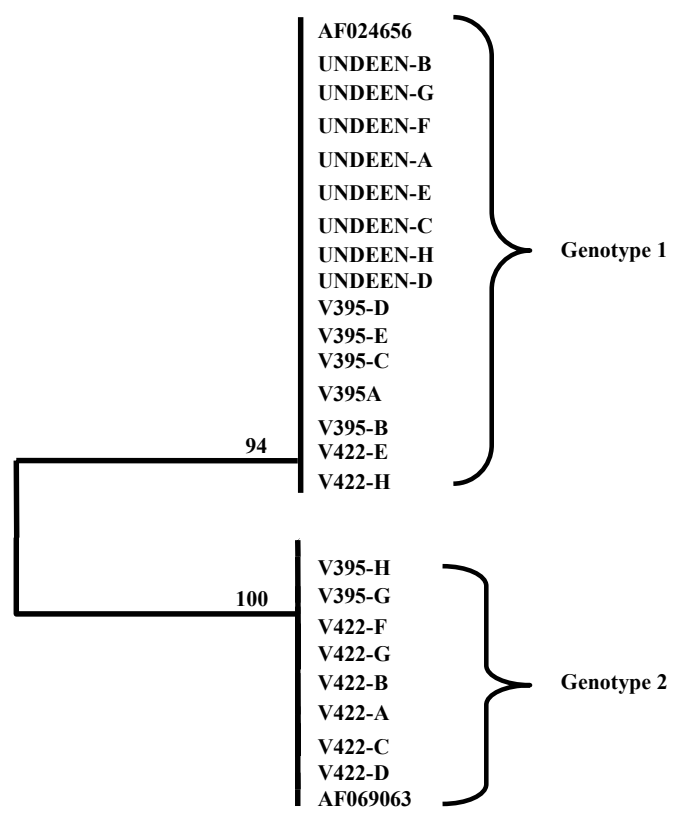

Fig. 8. The existence of mixed Brachiola algerae genotypes in isolates CDC:V395 and CDC:V422 as revealed by a UPGMA analysis of SSU rRNA sequences from cloned PCR products. Numbers on branches are percent bootstrapping values using 1,000 replicates.

resulted in noticeable changes in the proportion of each genotype. Similarly, cultivation of CDC:V404 and Undeen at $30^{\circ} \mathrm{C}$ or $37^{\circ} \mathrm{C}$ did not lead to the occurrence of the other genotype in each isolate. The occurrence of mixed genotypes was also stable over time, because the original specimen used in culture inoculation and early frozen culture of CDC:V395 also had the presence of mixed genotype 1 and genotype 2 sequences, and the proportion of each sequence was about the same as in parasites that had been continuously cultured for more than 1 year.

Despite the significant differences between the twogenotype sequences, they were apparently related as indicated by a phylogenetic analysis. A neighbour-joining tree constructed with these sequences and microsporidian SSU rRNA sequences retrieved from the GenBank consistently grouped the genotype 1 and 2 sequences together, indicating these two types of sequences were both from $B$. algerae. The closest relative of these $B$. algerae sequences were Thelohania solenopsae and Nosema acridophagus. Other Nosema spp. clustered in a separate clade together with Vairimorpha spp. (Fig. 9).

\section{DISCUSSION}

Members of the genus Brachiola like those of the genera Nosema and Vittaforma are characterized by the presence of a diplokaryon throughout their life cycle and are known to develop in direct contact with the host cell cytoplasm. Several cases of infection caused by three different species of Brachiola have been described (Sprague 1974,
Cali et al. 1991, 1998, 2004, Visvesvara et al. 1999a, Font et al. 2000, Coyle et al. 2004). In this report we discuss the continuous cultivation, morphologic, antigenic and molecular characterisation of three human isolates of $B . a l$ gerae and two mosquito isolates including the original Undeen isolate of $B$. algerae.

In vitro cultivation of microsporidial organisms that infect humans and animals is invaluable for several reasons. For example, it facilitates: (a) the understanding of the biology of the parasite and the host-parasite relationships; (b) the development of immunologic and molecular reagents for use in clinical diagnosis; (c) the development of assays for screening newer and promising therapeutic agents; and (d) the development of antigenic and molecular markers of the isolates that may be useful in molecular epidemiologic studies, particularly in tracking the sources of the causal agent, which will be helpful in formulating preventive strategies.

All isolates proliferated in monkey kidney (E6) cell and human lung fibroblast (HLF) monolayers and produced copious numbers of spores. No efforts, however, were made to determine the numbers of spores produced by the individual isolates At the light microscope level, no differences were seen in the development of the various human and mosquito isolates studied. Visual examination of the cultured isolates indicated that all isolates produced large numbers of spores. A most significant and characteristic feature was that all isolates proliferated initially as a ring around the host cell nucleus as shown in Fig. 1 and subsequently filled the entire cell with spores.

At transmission electron microscopy, all stages of the two human and the two mosquito isolates developed directly in contact with the host cell cytoplasm and all stages had a single diplokaryon. Another characteristic feature was the presence, in all isolates, of the vesiculotubular structures in close association with the membrane of the proliferative stages, indicating that these structures were produced by the parasite cell surface. In some cases these structures extended into the host cell cytoplasm. The vesiculotubular structure was also found free in the host cell cytoplasm, indicating that these structures dissociated from the parasite stages and accumulated within the host cell cytoplasm, as dense aggregates. This structure has been described previously by Vavra and Undeen (1970), Canning and Sinden (1973), and Moura et al. (1999) in mosquito-derived $B$. algerae, and by Visvesvara et al. (1999a) and Koudela et al. (2001) in mammalian cell culture and SCID mice infected with the human isolate of $B$. algerae, respectively. Further, Cali et al. (1998) described these structures in another species of Brachiola, B. vesicularum identified in a muscle biopsy of an HIV-infected patient with fever and progressive muscle weakness. The vesiculotubular structure observed here also extended into the host cell cytoplasm. These features have also been observed by Koudela et al. (2001) in liver tissue of SCID mice infected with a human isolate (CDC:V 404) and also 


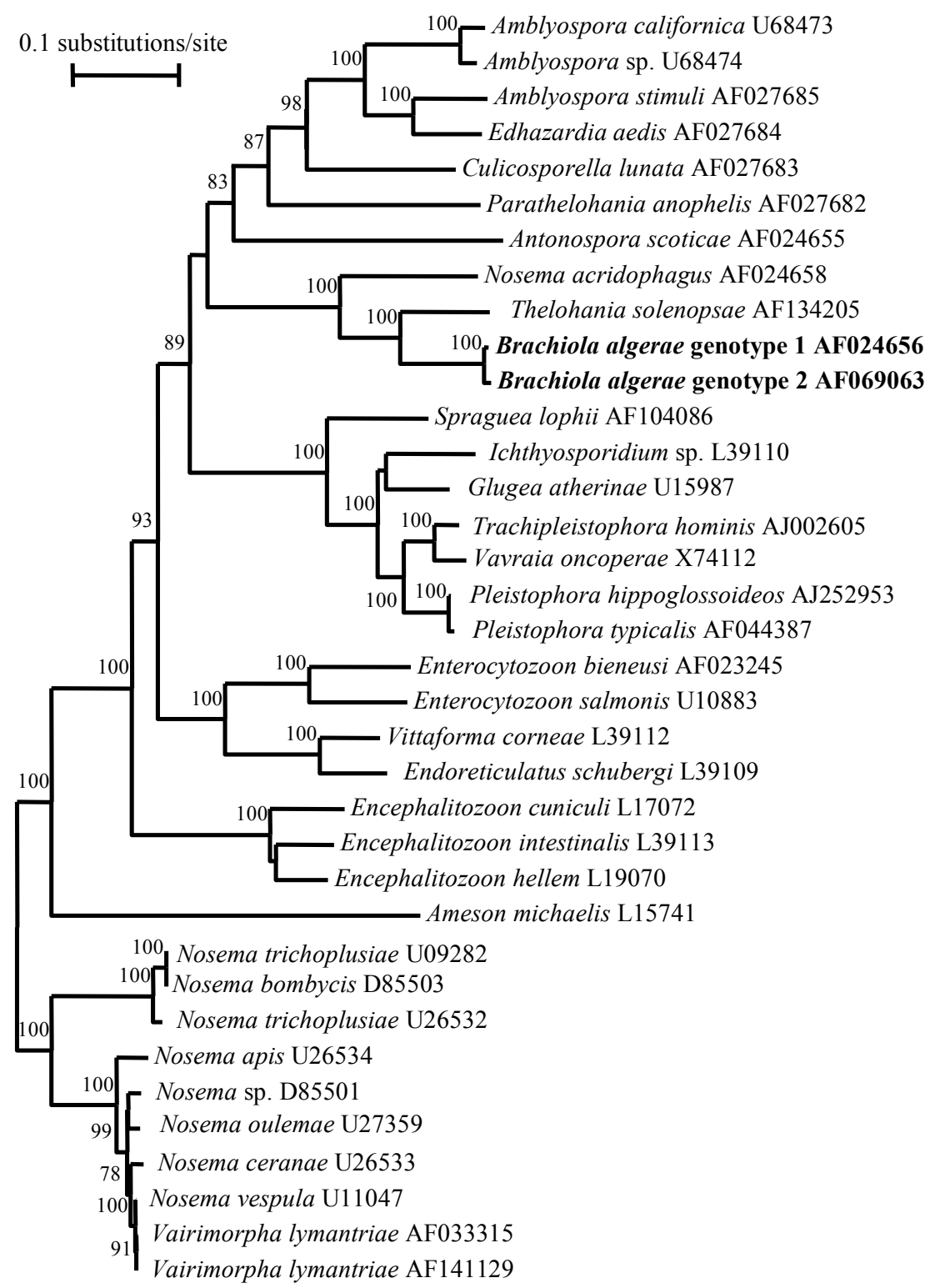

Fig. 9. Genetic relatedness of genotypes 1 and 2 of Brachiola algerae based on a neighbour-joining analysis of the sequences of the SSU rRNA gene. Numbers on branches are percent bootstrapping values using 1,000 replicates.

by Cali et al. (1998) in B. vesicularum that infected the human muscle tissue of an HIV-infected patient. Koudela et al. (2001) speculated that these vesiculotubular structures increase the surface area of the parasite cell, probably helping the parasite in absorbing nutrients from the host cell thus facilitating the development of this microsporidian. In a recent report, Cali et al. (2004) have compared the myositis isolate, newest of the human isolates, with the mosquito isolate by in vitro culture and electron microscopy and came to the conclusion that human and mosquito isolates are morphologically identical. They also state that the developmental pattern and parasite morphology of the myositis isolate is consistent with that of
CDC:V404 grown in SCID mice as described by Koudela et al. (2001).

Because $B$. algerae is typically a parasite of mosquitoes it was believed that the body temperature of mammalian host is a limiting factor for this parasite to jump from an invertebrate host to a mammalian host (Kucerova et al. 2004). However, previous reports indicate that the original mosquito strain of $B$. algerae can grow and proliferate in mammalian cell culture at $37^{\circ} \mathrm{C}$ (Undeen 1975, Moura et al. 1999, Trammer et al. 1999, Lowman et al. 2000). According to another recent report, human- and mosquitoderived isolates cultured in E6 cells at $30^{\circ}$ and $37^{\circ} \mathrm{C}$ differed in their ability to germinate and infect monkey 
kidney cells at these two temperatures (Kucerova et al. 2004). Further, the mosquito-derived isolate was also able to infect mice (Undeen and Alger 1976, Trammer et al. 1997, Cali et al. 2004) when they were injected into the footpad, or tail. The parasite grew only at the site of infection. A more recent report indicates that the humanderived isolate (CDC:V404) developed in the liver when the SCID mice were infected via surface of the eye but not when infected subcutaneously, perorally, intraperitoneally or intramuscularly (Koudela et al. 2001), indicating that although the parasite may be able to cross the temperature barrier it will have to face other barriers such as the immune status of the host and the immune defences mounted by the host.

Antigenic profiles of the isolates studied indicate that all isolates share some common antigenic determinants, based on the analysis of the immunoblots developed after reaction with the anti-rabbit serum generated against the human isolate (CDC:V404). Although all tested isolates of $B$. algerae had very similar antigenic profiles in the Western blot, minor differences were also noted. It is possible that these differences are due to relative differences in the growth phases of the organisms resulting in the expression of different proteins such as surface antigens or intracellular antigens. Since we had selected culture flasks of approximately same age and density of the parasites, it is therefore possible that these differences are indications of important variations between the isolates of $B$. algerae. Further work using proteins derived form culture flasks of different ages as well as different densities of parasites may provide answers to these observations.

Results of our molecular analysis have shown the presence of two $B$. algerae genotypes, which differ from each other by $1 \%$ in the sequence of the SSU rRNA gene. Because this is significantly smaller than the sequence differences between members of the same genus of microsporidia (for example, the sequence difference between two closely related Encephalitozoon spp., E. cuniculi No. L17072 and E. lacertae No. AF067144, is greater than $3 \%$ ), and because these two genotypes clustered together in the phylogenetic analysis of SSU RNA sequences of microsporidia, they are undoubtedly $B$. algerae. Genotypic variations have been previously seen in several humanpathogenic microsporidians, such as Enterocytozoon bieneusi, Encephalitozoon cuniculi and E. hellem (Didier et al. 1995, Rinder et al. 1997, Mathis et al. 1999). The stability of the two $B$. algerae genotypes that were maintained in continuous cultures for long periods of time and changes in culture temperature did not result in the selection of one genotype over the other in mixed isolates. Because of the multi-copy nature of the SSU rRNA gene, we cannot totally exclude the possibility of the existence of heterogeneous copies of the SSU rRNA gene in the genome of B. algerae. Nevertheless, it is apparent some isolates have only one genotype present whereas others have both genotypes. The fact that $B$. algerae infection is common in mosquitoes and both $B$. algerae genotypes 1 and 2 can infect humans suggests that mosquitoes can passively transmit microsporidian infections to humans by being swatted while biting. Thus, the transmission of human microsporidiosis can be not only zoonotic but also vectorborne. The occurrence of human microsporidiosis due to $B$. algerae may be underestimated. Previously, it was shown that a significantly high proportion of patients with unclassified ocular microsporidiosis had high titres of antibodies against B. algerae (Didier et al. 1991).

Case control studies conducted with HIV-infected individuals in Massachusetts, Texas and France identified swimming in rivers, lakes, and pools and drinking unfiltered tap or well water as risk factors. A possible waterborne outbreak of intestinal microsporidiosis due to $E$. bieneusi was reported in HIV+ and HIV- individuals in France (Watson et al. 1996, Hutin et al. 1998, Cotte et al. 1999). In one study, however, spores, of Nosema sp. and Pleistophora sp. have been found in ditch water in Florida (Avery and Undeen 1987). But it is not known whether some of the spores were actually of $B$. algerae, and whether $B$. algerae can induce human infection through the gastrointestinal tract. Additionally, it has been shown by Kelley and Anthony (1979) that spores of B. algerae survive UV radiation present in sunlight probably because dissolved organic materials in natural bodies of water would absorb large quantities of UV from solar radiation thus offering more protection for the spores. These authors have also shown that not only the spores survived even after exposure to direct sunlight for a period of up to 4 hours but also readily infected Anopheles albimanus mosquitoes. Further, some (at least 24\%) of B. algerae spores survived exposure to artificial ultraviolet radiation at 121 $\mu \mathrm{W} / \mathrm{cm}^{2}\left(0.06 \mathrm{~J} / \mathrm{cm}^{2}\right)$ for $2 \mathrm{~min}$, and infected anopheline mosquitoes (Kelley and Anthony 1979). In a different study high dosages of UV radiation were required to block germination (or extrusion of the polar tube) of the spore. Moreover, UV radiation of up to $3.8 \mathrm{~J} / \mathrm{cm}^{2}$ was found to stimulate $B$. algerae spores thus facilitating the germination process (Undeen and Vander Meer 1990). This clearly indicates that $B$. algerae spores can easily with-stand lower levels of UV radiation that occur in sun light. Apart from the few studies described above, information on the identification and prevalence of human-infecting microsporidia in environmental water sources, their concentrations or their frequency of occurrence is lacking. Waterborne transmission of microsporidia such as $B$. algerae therefore needs to be studied and better understood as a cause of microsporidiosis including corneal, cutaneous etc. infections, in humans.

The spores of B. algerae are small, hardy, and resistant to a number of physical and chemical pressures in the environment and may survive and pass through conventional drinking water treatment plants and hence present a potential threat to human health. Therefore, the role of drinking water in the epidemiology of these parasites need to be studied. Unfortunately, routine methods for the detection of the various human-infecting microsporidia in the envi- 
ronment, especially in water, are lacking. Therefore, methods for recovering spores of $B$. algerae and other microsporidia with high efficiency from the environment, especially water, and the detection of viable or infectious spores need to be developed since these parasites represent a threat to public health.
Acknowledgements. Gordon J. Leitch was supported in part by Public Health Service grant RR03034. The authors extend their thanks to Drs. John D. Goosey, Mary E. Landau-Levine and Luther V. Rhodes III for providing specimens from patients 1, 2 and 3 respectively, to Rama Sriram for technical assistance and James Gathany for help with the photographs.

\section{REFERENCES}

AVERY S.W., UNDEEN A.H: 1987: The isolation of microsporidia and other pathogens from concentrated ditch water. J. Am. Mosq. Control Assoc. 3: 54-58.

BAKER M.D., VOSSBRINCK C.R., MADDOX J.V., UNDEEN A.H. 1994: Phylogenetic relationships among Vairimorpha and Nosema species (Microspora) based on ribosomal RNA sequence data. J. Invertebr. Pathol. 64: 100-106.

CALI A., MEISLER D.M., LOWDER C.Y., LEMBACH R., AYERS L., TAKVORIAN P.M., RUTHERFORD I., LONGWORTH D.L., McMAHON J.T., BRYAN R.T. 1991: Corneal microsporidiosis: characterization and identification. J. Protozool. 38: 215S-217S.

CALI A., TAKVORIAN P.M., LEWIN S., RENDEL M., SIAN C.S., WITTNER M., TANOWITZ H.B., KEOHANE E., WEISS L.M. 1998: Brachiola vesicularum, n. g., n. sp., a new microsporidium associated with AIDS and myositis. J. Eukaryot. Microbiol. 45: 240-251.

CALI A., WEISS L.M., TAKVORIAN P.M. 2004: An analysis of the microsporidian genus Brachiola, with comparisons of human and insect isolates of Brachiola algerae. J. Eukaryot. Microbiol. 51: 678-685.

CANNING E.U., SINDEN R.E. 1973: Ultrastructural observations on the development of Nosema algerae Vavra and Undeen (Microsporida, Nosematidae) in the mosquito Anopheles stephensi Liston. Protistologica 9: 405-413.

COTTE L., RABODONIRINA M., CHAPUIS F., BAILLY F., BISSUEL F., RAYNAL C., GELAS P., PERSAT F., PIENS A., TREPO C. 1999: Waterborne outbreak of intestinal microsporidiosis in persons with and without human immunodeficiency virus infection. J. Infect. Dis. 180: 2003-2008.

COYLE C.M., WEISS L.M., RHODES L.V. III, CALI A., TAKVORIAN P.M., BROWN B.F., VISVESVARA G.S., XIAO L., NAKTIN J., YOUNG E., GARECA M., COLASANTE G., WITTNER M. 2004: Fatal myositis due to the microsporidian Brachiola algerae, a mosquito pathogen. N. Engl. J. Med. 351: 42-47.

DIDIER E.S., BESSINGER T.D. 1999: Host-parasite relationships in microsporidiosis: animal models and immunology. In: M. Wittner and L.M. Weiss (Eds.), Microsporidia and Microsporidiosis. ASM Press, Washington, D.C., pp. 225257.

DIDIER E.S., SHADDUCK J.A., DIDIER P.J., MILLICHAMP N., VOSSBRINCK C.R. 1991: Studies on ocular microsporidia. J. Protozool. 38: 635-638.

DIDIER E.S., VOSSBRINCK C.R., BAKER M.D., ROGERS L.B., BERTUCCI D.C., SHADDUCK J.A. 1995: Identification and characterization of three Encephalitozoon cuniculi strains. Parasitology 111: 411-421.

DOWD S.E., GERBA C.P., PEPPER I.L. 1998: Confirmation of the human-pathogenic microsporidia Enterocytozoon bie- neusi, Encephalitozoon intestinalis, and Vittaforma corneae in water. Appl. Environ. Microbiol. 64: 3332-3335.

FONT R.L., SAMAHA A.N., KEENER M.J., CHEVEZBARRIOS P., GOOSEY J.D. 2000: Corneal microsporidiosis: report of case, including electron microscopic observations. Ophthalmology 107: 1769-1775.

HUTIN Y.J.F., SOMBARDIER M.N., LIGOURY O., SARFATI C., DEROUIN F., MODAI J., MOLINA J.-M. 1998: Risk factors for intestinal microsporidiosis in patients with human immunodeficiency virus infection: a case control study. J. Infect. Dis. 178: 904-907.

KELLEY J.F., ANTHONY D.W. 1979: Susceptibility of spores of the microsporidian Nosema algerae to sunlight and germicidal ultraviolet radiation. J. Invertebr. Pathol. 34: 164169.

KOUDELA B., VISVESVARA G.S., MOURA H., VÁVRA J. 2001: The human isolate of Brachiola algerae (Phylum Microspora): development in SCID mice and description of its fine structure. Parasitology 123: 153-162.

KUCEROVA Z., MOURA H., VISVESVARA G.S., LEITCH G.J. 2004: Differences between Brachiola (Nosema) algerae isolates of human and insect origin when tested using an in vitro spore germination assay and a cultured cell infection assay. J. Eukaryot. Microbiol. 51: 339-343.

LOWMAN P.M., TAKVORIAN P.M., CALI A. 2000: The effects of elevated temperature and various time-temperature combinations on the development of Brachiola (Nosema) algerae n. comb. in mammalian cell culture. J. Eukaryot. Microbiol. 47: 221-234.

MATHIS A., TANNER I., WEBER R., DEPLAZES P. 1999: Genetic and phenotypic intraspecific variation in the microsporidian Encephalitozoon hellem. Int. J. Parasitol. 29: 767770.

MOURA H., DA SILVA A.J., MOURA I.N.S., SCHWARTZ D.A., LEITCH G.J., WALLACE S., PIENIAZEK N.J., WIRTZ R.A., VISVESVARA G.S. 1999: Characterization of Nosema algerae isolates after continuous cultivation in mammalian cells at $37^{\circ} \mathrm{C}$. J. Eukaryot. Microbiol. 46: 14S$16 \mathrm{~S}$.

MOURA H., SCHWARTZ D.A., BORNAY-LLINARES F., SODRE F.C., WALLACE S., VISVESVARA G.S. 1997: A new and improved "quick-hot Gram-chromotrope" technique that differentially stains microsporidian spores in clinical samples including paraffin-embedded tissue sections. Arch. Pathol. Lab. Med. 121: 888-893.

MULLER A., TRAMMER T., CHIORALIA G., STEITZ H.M., DIEHL V., FRANZEN C. 2000: Ribosomal RNA of Nosema algerae and phylogenetic relationship to other microsporidia. Parasitol. Res. 86: 18-23. 
RINDER H., KATZWINKEL-WLADARSCH S., LOSCHER T. 1997: Evidence for the existence of genetically distinct strains of Enterocytozoon bieneusi. Parasitol. Res. 83: 670 672.

SPRAGUE V. 1974: Nosema connori, n. sp., a microsporidian parasite of man. Trans. Am. Microsc. Soc. 93: 400-403.

TRAMMER T., CHIORALIA G., MAIER W.A., SEITZ H.M. 1999: In vitro replication of Nosema algerae (Microsporidia), a parasite of anopheline mosquitoes, in human cells above $36^{\circ} \mathrm{C}$. J. Eukaryot. Microbiol. 46: 464-468.

TRAMMER T., DOMBROWSKI F., DOEHRING M., MAIER W.A., SEITZ H.M. 1997: Opportunistic properties of Nosema algerae (Microspora), a mosquito parasite, in immunocompromised mice. J. Eukaryot. Microbiol. 44: 258 262.

UNDEEN A.H. 1975: Growth of Nosema algerae in pig kidney cell cultures. J. Protozool. 22: 107-110.

UNDEEN A.H., ALGER N.E. 1976: Nosema algerae: infection of the white mouse by a mosquito parasite. Exp. Parasitol. 40: 86-88.

UNDEEN A.H., VANDER MEER R.K. 1990: The effect of ultraviolet radiation on the germination of Nosema algerae Vávra and Undeen (Microsporida: Nosematidae) spores. J. Protozool. 37: 194-199.

VAN DE PEER Y., DE WACHTER R. 1994: TREECON for Windows - a software package for the construction and drawing of evolutionary trees for the Microsoft Windows environment. Comput. Applic. Biosci. 10: 569-570.

VAVRA J., UNDEEN A.H. 1970: Nosema algerae n.sp. (Cnidospora, Microsporida) a pathogen in laboratory colony of Anopheles stephensi Liston (Diptera, Culicidae). J. Protozool. 17: 240-249.

VISVESVARA G.S., BELLOSO M., MOURA H.M., DA SILVA A.J., MOURA I.N.S., LEITCH G.J., SCHWARTZ D.A., CHEVEZ-BARROIS P., WALLACE S., PIENIAZEK
N.J., GOOSEY J.D. 1999a: Isolation of Nosema algerae from the cornea of an immunocompetent patient. J. Eukaryot. Microbiol. 46: 10S.

VISVESVARA G.S., LEITCH G.J., DA SILVA A.J., CROPPO G.P., MOURA H., WALLACE S., SLEMENDA S.B., SCHWARTZ D.A., MOSS D.M., BRYAN R.T., PIENIAZEK N.J. 1994: Polyclonal and monoclonal antibody and PCR-amplified small subunit rRNA identification of a microsporidian, Encephalitozoon hellem, isolated from an AIDS patient with disseminated infection. J. Clin. Microbiol. 32: 2760-2768.

VISVESVARA G.S., LEITCH G.J., MOURA H., WALLACE S., WEBER R., BRYAN R.T. 1991: Culture, electron microscopy, and immunoblot studies on a microsporidian parasite isolated from the urine of a patient with AIDS. J. Protozool. 38: 105S-111S.

VISVESVARA G.S., MOURA H., LEITCH G.J., SCHWARTZ D.A. 1999b: Culture and propagation of microsporidia. In: M. Wittner and L.M. Weiss (Eds.), Microsporidia and Microsporidiosis. ASM Press, Washington, D.C., pp. 363-392.

WATSON D.A.R., ASMUTH D., WANKE C.A. 1996: Environmental risk factors for acquisition of microsporidia in HIV-infected persons. Program and abstracts: 34th annual meeting of the Infectious Disease Society of America, Abstract 235 .

WEBER R., BRYAN R.T., OWEN R.L., WILCOX C.M., GORELKIN L., VISVESVARA G.S. 1992: Improved light microscopical detection of microsporidia spores in stool and duodenal aspirates. N. Engl. J. Med. 326: 161-166.

WEISS L.M., VOSSBRINCK C.R. 1999: Molecular biology, molecular phylogeny, and molecular diagnostic approaches to the Microsporidia. In: M. Wittner and L.M. Weiss (Eds.), Microsporidia and Microsporidiosis. ASM Press, Washington, D.C., pp. 129-195.

Accepted 28 March 2005 